Canadian

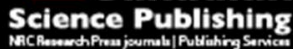

Canadian Geotechnical Journal Revue canadienne de géotechnique

\title{
Probabilistic seismic hazard site assessment in Kitimat, British Columbia, from Bayesian inversion of surface-wave dispersion
}

\begin{tabular}{|r|l|}
\hline Journal: & Canadian Geotechnical Journal \\
\hline Manuscript ID & cgj-2017-0265.R2 \\
\hline Manuscript Type: & Article \\
\hline Date Submitted by the Author: & 10 -Sep-2017 \\
\hline Complete List of Authors: & $\begin{array}{l}\text { Gosselin, Jeremy; University of Victoria, School of Earth and Ocean } \\
\text { Sciences } \\
\text { Cassidy, John; University of Victoria, School of Earth and Ocean Sciences; } \\
\text { Natural Resources Canada } \\
\text { Dosso, Stan; University of Victoria, School of Earth and Ocean Sciences } \\
\text { Brillon, Camille; Natural Resources Canada }\end{array}$ \\
\hline $\begin{array}{r}\text { Is the invited manuscript for } \\
\text { consideration in a Special } \\
\text { Issue? : }\end{array}$ & N/A \\
\hline Keyword: & $\begin{array}{l}\text { Seismic site assessment, Ambient seismic noise, Inverse Problems, Surface } \\
\text { Waves }\end{array}$ \\
\hline &
\end{tabular}

SCHOLARONE ${ }^{m}$

Manuscripts 
1. Probabilistic seismic hazard site assessment in Kitimat, . British Columbia, from Bayesian inversion of surface-wave

3 dispersion

4 Jeremy M. Gosselin*1, John F. Cassidy ${ }^{\dagger 1,2}$, Stan E. Dosso ${ }^{\ddagger 1}$ and Camille 5 Brillon $^{\S 2}$

- ${ }^{1}$ School of Earth and Ocean Sciences, University of Victoria, Victoria, BC, V8W 3P6, Canada

8 ${ }^{2}$ Natural Resources Canada, Sidney, BC, V8L 4B2, Canada

$9 \quad$ Contribution Number: 20170045

*Communicating author: jeremyg@uvic.ca

†john.cassidy@canada.ca

${ }^{\ddagger}$ sdosso@uvic.ca

§camille.brillon@canada.ca 
Probabilistic seismic hazard site conditions in Kitimat, British Columbia, from Bayesian inversion of surface-wave dispersion

Jeremy M. Gosselin, John F. Cassidy, Stan E. Dosso, and Camille Brillon

\section{Abstract}

This paper applies rigorous quantitative inversion methods to estimate seismic-hazard site classification and amplification factors in Kitimat, British Columbia, due to near-surface geophysical conditions. Frequency-wavenumber seismic-array processing is applied to passive data collected at three sites in Kitimat to estimate surface-wave dispersion. The dispersion data are inverted using a fully nonlinear Bayesian (probabilistic) inference methodology to estimate shear-wave velocity $\left(V_{S}\right)$ profiles and uncertainties. The $V_{S}$ results are used to calculate the travel-time average of $V_{S}$ to $30 \mathrm{~m}$ depth $\left(V_{S 30}\right)$ as a representation of the average soil/sediment conditions, and to determine seismic-hazard site classification with respect to the National Building Code of Canada. In addition, $V_{S 30^{-}}$dependent site amplification factors are computed to estimate site amplification at the three Kitimat sites. Lastly, the $V_{S}$ profiles are used to compute amplification and resonance spectra for horizontally-polarized shear waves. Quantitative uncertainties are estimated for all seismic-hazard estimates from the probabilistic $V_{S}$ structure. The Kitimat region is the site for several proposed large-scale industrial development projects. One of the sites considered in this study is co-located with a recently-deployed soil seismographic monitoring station that is currently recording ground motions as part of a 5-year campaign. The findings from this work will be useful for mitigating seismic amplification and resonance hazards on critical infrastructure, as well as for future seismological research, in this environmentally- and economically-significant region of Canada.

Keywords: Seismic site assessment, Ambient seismic noise, Inverse problems, Surface waves 


\section{${ }_{34}$ Introduction}

Estimating site-specific seismic amplification and resonance hazards is important for engineers and planners in designing plans that can mitigate damage caused by earthquakes, protect critical infrastructure, and potentially save lives. These site-specific hazards depend predominantly on near-surface geophysical properties such as shear-wave velocity $\left(V_{S}\right)$, compressional-wave velocity $\left(V_{P}\right)$, and density $(\rho)$. It is well known that seismic-wave amplitude increases as waves propagate through material of decreasing impedance, such as soft/loose near-surface sediments (Anderson et al. 1986, 1996). Amplification can also occur at particular frequencies due to resonance within near-surface low-velocity layers. Seismic body-waves can also become trapped, focused, and converted into long-period surface waves due to three-dimensional (3-D) basin structures, which can significantly amplify and extend the duration of earthquake shaking (e.g., Bard and Bouchon 1980; Graves et al. 1998). For these reasons, estimating the near-surface structure of geophysical properties (particularly $V_{S}$ ) is critical for understanding and predicting site-specific seismic amplification and resonance hazards.

Currently, many site-response classifications and ground-motion models (GMM) rely on the travel-time average of $V_{S}$ over the upper $30 \mathrm{~m}$, known as $V_{S 30}$ (e.g., Boore and Atkinson 2008; Seyhan and Stewart 2014). By definition, $V_{S 30}$ is weighted more heavily toward lowvelocity material, which generally cause seismic-wave amplification. The National Earthquake and Hazards Reduction Program (NEHRP) uses a classification scheme for site-specific seismic hazard according to six site classes (A-F) based primarily on ranges of estimated or measured $V_{S 30}$ values (FEMA Provision 750 2009). The National Building Code of Canada (NBCC) adopts a similar classification scheme (Table 1) and assigns site amplification factors of earthquake ground acceleration based on this classification (Finn and Wightman 2003; NBCC 2010; Humar 2015). These amplification factors are used for design procedures and are incorporated in Canada-wide seismic hazard models (e.g., Adams et al. 2015). The $V_{S 30}$ classification scheme reduces the dependence of site amplification on earthquake properties and propagation effects by averaging over empirical amplification measurements from many earthquake recordings (Borcherdt 1994). However, there is not universal agreement that $V_{S 30}$ is a valid proxy for seismic amplification, particularly for complex $V_{S}$ profiles with impedance discontinuities within the upper 30 m (Castellaro et al. 2008; Lee and Trifunac 2010; Molnar et al. 2013). 
$V_{S}$ profiles at a site can be determined by invasive methods such as boreholes or seismic cone penetration tests (SCPT). $V_{S}$ profiles can also be inferred from non-invasive, active or passive seismic methods. Passive seismic methods have become increasingly popular due to their reduced demands in terms of cost and logistics. An attractive approach is to estimate the dispersion of fundamental-mode Rayleigh waves using array recordings of ambient seismic noise (Aki 1957; Lacoss et al. 1969; Wathelet et al. 2008; Molnar et al. 2010). Dispersion occurs due to the nature of propagation of Rayleigh waves, where lower-frequency waves are more sensitive to geophysical properties at greater depth than higher-frequency waves. Hence, the velocity-frequency relationship (dispersion curve) of Rayleigh waves can be inverted to estimate profiles of geophysical properties.

More costly and complex active-source seismic methods for estimating two-dimensional (2D) $V_{S}$ models include high-resolution, multi-component seismic-reflection surveys (e.g., Pugin et al. 2009, 2013). Such surveys use a swept-frequency vibratory source and a dense linear array of three-component geophones. $V_{P}$ and $V_{S}$ values are extracted using semblance analysis and then converted into interval velocities using a modified Dix equation that takes into account the increase of Vs with depth (Pugin et al. 2013).

This work applies passive seismic array processing to estimate dispersion data at three locations in Kitimat, British Columbia (BC), Canada (Fig. 1). Bayesian inference is applied to probabilistically estimate parameters of a geophysical model using observed dispersion data and prior information. In the inversion, the geophysical model is parameterized as smooth, gradient-based profiles in terms of a Bernstein-polynomial representation (Quijano et al. 2016; Gosselin et al. 2017). The most-probable $V_{S}$ profile as well as quantitative measures of the profile uncertainty are determined within the Bayesian framework. The inversion results are considered here in terms of marginal probability profiles for $V_{S}$ which are estimated numerically using Markov-chain Monte Carlo (MCMC) sampling of the posterior probability density (PPD) of the model parameters (Mosegaard and Tarantola 1995; Brooks et al. 2011). Inversion results for $V_{S}$ are compared to estimates from an active-source seismic-reflection survey conducted by the Geological Survey of Canada (GSC) (Pugin et al. 2017). From the $V_{S}$ marginal probability profiles, probability densities for the travel-time average of $V_{S}$ to an arbitrary depth $z$ (called $V_{S Z}$ here) are computed as a representation of the average soil/sediment conditions at each site 
(Molnar et al. 2013). In addition, probability densities of $V_{S 30}$, and site-amplification factors dependent on $V_{S 30}$, are computed to provide estimates (with quantitative uncertainties) of the seismic-hazard site classification and predicted site amplification at the three Kitimat sites. Lastly, the $V_{S}$ marginal density profiles are used to compute probabilistic amplification and resonance spectra for horizontally-polarized shear $\left(S_{H}\right)$ waves (Molnar et al. 2013).

The town of Kitimat is located on the farthest inland reach of one of the largest fjords on the BC coast, the Douglas Channel (Fig. 1). The Douglas Channel and its inland expression, which extends over $90 \mathrm{~km}$ northward, form a single continuous glacial valley (Dolmage 1956). Bedrock geology in the region consists mainly of granitic rocks of the Canadian Cordillera Coast Mountain Batholith, consistent with bedrock found along the BC coast from Vancouver to Alaska (Dolmage 1956). Thick deposits of glacial till overlie bedrock and were left behind during deglaciation of the Cordilleran ice sheet in the late Pleistocene (Bornhold 1983; Clague 1984). As glaciers retreated, marine and deltaic sediments were deposited on the isostaticallydepressed coastal region before sea level dropped to present day levels. The region is also overlain with Holocene deltaic and surficial floodplain sediments from the Kitimat River (Dolmage 1956; Clague 1977). Past drillings southwest of the Municipal District of Kitimat indicate sediment thicknesses can exceed 100 m (Dolmage 1956), while studies within the Douglas Channel indicate Holocene sediments are up to $60 \mathrm{~m}$ thick and overlie several hundred metres of older glacial material (Bornhold 1983).

There exists a relative gap in the knowledge of the seismicity of the region, compared to coastal areas to the north and south, due to a lack of seismic instrumentation. Studies since the installation of new instruments in the region in 2014 do not indicate any previously unknown areas of seismicity (Brillon 2016b). Recent studies have identified a fault-like structure in the Douglas Channel which might have triggered submarine landslides during the early Holocene, suggesting the fault is active (Conway et al. 2012). Of more obvious concern, Kitimat is located within $300 \mathrm{~km}$ of Haida Gwaii and the Queen Charlotte Fault zone, which is one of the most seismically-active regions in Canada and site of the two largest instrumentally-recorded earthquakes in Canadian history with magnitudes of 8.1 and 7.8 in 1949 and 2012, respectively (Bostwick 1984; Cassidy et al. 2014). The 2012 event was felt as far away as Alberta and the Yukon (over $1000 \mathrm{~km}$ ). 
The Kitimat region and surrounding shoreline are the sites for several proposed large-scale industrial development projects including export facilities for heavy oil and natural gas. As such, the region has great environmental and economic significance for Canada, and the GSC is currently investigating geological hazards in the region (e.g., Conway et al. 2012; Crow et al. 2015; Brillon et al. 2015; Brillon 2016a,b; Pugin et al. 2017). The findings on amplification and resonance from this research will be useful for engineers, planners, and regulatory agencies to mitigate the hazards on the environment and on critical infrastructure. Furthermore, one of the sites considered in this study is co-located with a recently-deployed soil seismographic monitoring station that is currently recording ground motions as part of a 5-year campaign. As a result, the findings from this work will also be useful for future seismological research. Specifically, site corrections derived from the $V_{S}$ structure estimated in this study will be applied to on-going measurements from this new soil station. In addition, site assessment estimates presented here may provide a baseline for comparison with future empirical site assessment studies in Kitimat.

\section{Field work and data processing}

This section describes the field work and data-processing procedures used to estimate dispersion data from passive seismic array recordings at sites 1-3 in Kitimat BC, as shown in Fig. 2. The locations for the array recordings were chosen based on a combination of factors including sufficient space to carry out the survey, relatively flat topography, proximity to potential noise sources, and accessibility. Kitimat site 1 is located near part of an active-source seismic reflection survey (which provides a useful comparison to results from this study). Kitimat site 3 is co-located with a recently-deployed soil seismographic monitoring station. At each site, a cross-shaped array of five seismic stations was deployed in four different array sizes with inter-station distances (distance to the centre station) ranging from $5 \mathrm{~m}$ to $45 \mathrm{~m}$. Fig. 3 shows a photograph of a single-instrument installation. Each station consists of a three-component broadband seismometer connected to a digitizer and recorder, a battery power supply, and a GPS antenna for synchronous timing. To deploy the seismometers, the surficial layer of vegetation (grass, moss, etc.) was removed and a ceramic tile laid down to achieve better coupling to the ground surface. Approximately one hour of ambient seismic noise was recorded for each 
array configuration. The multiple array configurations (with different station separations) allow for a relatively wide dispersion frequency band to be estimated.

This study applies frequency-wavenumber $(f-k)$ processing to estimate the slowness (reciprocal of phase velocity) of the fundamental-mode Rayleigh wave as a function of frequency from passive seismic array recordings (Lacoss et al. 1969; Wathelet et al. 2008). Only verticalcomponent recordings are used here, such that ambient-noise recordings are assumed to be dominated by Rayleigh waves. Dispersion data were computed for 50 logarithmically-spaced frequencies between 1 and $12 \mathrm{~Hz}$ for all array configurations, at every site. However, only the data within a specific wavenumber band (defined by the resolution and aliasing limits of the array) are retained and used in inversion. These limits depend on the inter-station distances and spatial distribution of the stations and are estimated here using the methodology described by Wathelet et al. (2008). Fig. 4 shows the array configurations and processed dispersion data for Kitimat site 1 (similar array installations were used at sites 2 and 3). The dispersion data of a particular colour were processed from the array configuration of the corresponding colour (the centre station being common to all array configurations). One standard deviation error bars show the level of confidence of the f-k processing (similar errors are estimated at sites 2 and 3), but do not represent the data errors considered within the inversion (discussed in the next section). The red line in Fig. 4 represents a section of a multi-component seismic-reflection survey used for comparison of inversion results at site 1.

\section{Inversion of surface-wave dispersion data}

This section considers the inversion of Rayleigh-wave dispersion data extracted from passive array recordings collected at the three Kitimat sites. The dispersion data are inverted using the Bayesian inversion methodology summarized here but developed in detail in Gosselin et al. (2017). Specifically, consider a vector of $N$ data $\mathbf{d}$ (in this case, the Rayleigh-wave dispersion data) and a vector of $M$ model parameters $\mathbf{m}$ (that describe the geophysical parameter profiles), with both assumed to be random variables. Bayes' theorem can be written as

$$
P(\mathbf{m} \mid \mathbf{d}, H)=\frac{P(\mathbf{m} \mid H) P(\mathbf{d} \mid \mathbf{m}, H)}{P(\mathbf{d} \mid H)},
$$


where $H$ is the choice of model (e.g., the earth parameterization). The term $P(\mathbf{m} \mid H)$ is the probability of a set of model parameters $\mathbf{m}$, given model $H$, independent of the data, and represents the prior information. $P(\mathbf{d} \mid \mathbf{m}, H)$ is the conditional probability of $\mathbf{d}$ given $\mathbf{m}$ and is interpreted as the likelihood of $\mathbf{m}$, written $\mathcal{L}(\mathbf{m})$ (for fixed model $H$ ). $P(\mathbf{m} \mid \mathbf{d}, H$ ) is the PPD, representing the probability density over the model parameters given the data, prior information, and choice of model. $P(\mathbf{d} \mid H)$ is the probability of the data for a given model $H$, independent of $\mathbf{m}$, known as the Bayesian evidence for $H$, and provides normalization over the parameter space.

Estimating properties of the PPD, such as the maximum a posteriori (MAP) model $\hat{\mathbf{m}}$ and marginal probability densities, provides the model parameters and associated uncertainties. However, for non-linear inverse problems, analytic solutions generally do not exist and numerical methods are required. Specifically, the Metropolis-Hastings algorithm is a MCMC method used here to draw a series of dependent, asymptotically-unbiased samples from the PPD (Metropolis et al. 1953; Hastings 1970; Brooks et al. 2011). In this study, the prior probability density consists of a bounded uniform distribution constraining parameters to geophysically-realistic values (Table 2). Wide bounds are applied to allow the data information, instead of the prior information, to primarily determine the solution. A sufficiently large set of MCMC samples can be used to approximate the PPD.

The likelihood function is formulated by specifying the statistical distribution of the data errors. The data error distribution is often not known independently, as it must include both theory and measurement errors (which typically cannot be distinguished). In many cases, a multi-variate Gaussian distribution is a reasonable assumption (supported by the Central Limit Theorem). Instead of fixing the data variances to those estimated from the $f$ - $k$ processing (errors bars in Fig. 4), which do not include theory errors and may not fully represent the error processes, the error statistics are considered unknown and included in the inverse problem. However, instead of including the data variance as explicit unknowns and neglecting error correlations, a more general and elegant approach is used here. A likelihood function is applied which samples implicitly over maximum-likelihood estimates of variance. A complete derivation of this likelihood function is given in Dosso and Wilmut (2006) and leads to

$$
\mathcal{L}(\mathbf{m}) \propto \exp \left[-\frac{N}{2} \log _{e}|\mathbf{r}(\mathbf{m})|^{2}\right],
$$


where

$$
\mathbf{r}(\mathbf{m})=\mathbf{d}-\mathbf{d}(\mathbf{m})-\tilde{\mathbf{r}}(\mathbf{m}, a)
$$

are the total data residuals, and $\mathbf{d}(\mathbf{m})$ are the data predicted for model $\mathbf{m}$. The total residuals account for a first-order auto-regressive (AR) process to compensate for data-error correlations with elements of the vector $\tilde{\mathbf{r}}(\mathbf{m}, a)$ determined according to (Shumway and Stoffer 2000)

$$
\tilde{r}_{i}(\mathbf{m}, a)=a\left(d_{i-1}-d_{i-1}(\mathbf{m})\right)
$$

where $a$ is the AR parameter, which is considered unknown in the inversion (Dettmer et al. 2012). The total residuals are treated as uncorrelated and Gaussian distributed with this representation. A posteriori statistical tests are applied to the standardized residuals to check the assumptions of the data-error model.

The data are treated in terms of slowness (the reciprocal of phase velocity) because the $f$ - $k$ processing discussed in the previous section estimates the wavenumber of propagating Rayleigh waves, and errors in slowness scale linearly with errors in the estimated wavenumber. For slowness data with constant variance, this produces phase velocities with larger errors at low frequencies, which is believed to be a physically-reasonable representation of the frequency dependence of the data errors. The calculation of predicted dispersion data for candidate earth models is performed using the software developed by Wathelet (2005). This software requires density profiles as an input, which is found to be relatively insensitive to dispersion data. For this reason, density profiles are computed directly within the inversion using an empirical relationship with $V_{P}$ (Gardner et al. 1974). Hence, only profiles of $V_{S}$ and $V_{P} / V_{S}$ are estimated here.

The ability to represent general earth structure using a simple functional form is a useful characteristic of a model parameterization in Bayesian inversion. The $V_{S}$ and $V_{P} / V_{S}$ profiles are parameterized in terms of a Bernstein-polynomial representation overlaying a half-space (a semi-infinite basement layer with uniform properties). This representation is a general and efficient approach to parameterizing smooth gradient-based profiles, and is considered appropriate here as gradient-based profiles are expected due to the thick sequences of Holocene sediment lithology. This is also believed to be consistent with the resolution of surface-wave 
dispersion data, which are not sensitive to fine-scale structure. The Bernstein polynomial is defined over the interval $0<z<z_{0}$ by

$$
u(\tilde{z})=\sum_{j=0}^{J^{u}} g_{j}^{u} b_{j}\left(\tilde{z}, J^{u}\right),
$$

where $u$ is the parameter being represented in polynomial form $\left(V_{S}\right.$ or $\left.V_{P} / V_{S}\right), \tilde{z}=z / z_{0}$ is the normalized depth $\left(z_{0}\right.$ is the maximum depth of the polynomial representation), $J^{u}$ is the order of the Bernstein polynomial for parameter $u, g_{j}^{u}$ are coefficients, and

$$
b_{j}\left(\tilde{z}, J^{u}\right)=\left(\begin{array}{c}
J^{u} \\
j
\end{array}\right)(1-\tilde{z})^{\left(J^{u}-j\right)} \tilde{z}^{j}
$$

are the Bernstein basis functions. Because the basis functions are fixed, only the coefficients, maximum depth $z_{0}$, and parameters of the underlying halfspace are treated as unknowns within the inversion (as well as the AR parameter discussed above).

The Bernstein-polynomial parameterization applied here has the effect of regularizing the inversion with a preference for smoothly-varying gradient structure, and is well suited to cases where this is consistent with prior information. The passive-array seismic data considered in this paper are limited to wavelengths of greater than approximately $20 \mathrm{~m}$, and hence provide limited information to resolve structural variations within the uppermost 10-20 m. Bayesian inversion based on Bernstein polynomials may under-estimate $V_{S}$ uncertainties over these depths if the prior expectation of smooth gradients is not realized. Nonetheless, the approach is sufficient for the estimation of general $V_{S}$ structure, and $V_{S 30}$ determination (with representative uncertainties).

The inversion is performed for several Bernstein-polynomial orders given by $J^{V_{S}}$ and $J^{V_{P} / V_{S}}$ for the $V_{S}$ and $V_{P} / V_{S}$ profiles, respectively. The Bayesian information criterion (BIC), which represents an asymptotic point-estimate of Bayesian evidence, is computed for the maximumlikelihood model in the Markov chains for each inversion to determine the simplest model consistent with the resolving power of the data (Schwartz 1978; Kass and Raftery 1995). Given the uniform prior densities, the maximum-likelihood model corresponds to the MAP model $\hat{\mathbf{m}}$ (most probable set of model parameters in the Markov chain). The optimal polynomial order is the one that minimizes the BIC, and so the final inversion results are shown for this 
parameterization. The BIC is a minimum for $J^{V_{S}}=2$ and $J^{V_{P} / V_{S}}=1$ for sites 1 and 3 , and is a minimum for $J^{V_{S}}=3$ and $J^{V_{P} / V_{S}}=1$ for site 2 .

Figs. 5, 6, and 7 show the results of the inversion in the form of marginal probability profiles for $V_{S}$ at Kitimat sites 1, 2, and 3, respectively. The $V_{S}$ marginal profiles at each site shows clear depth-dependent structure with velocities increasing with depth. Results for sites 2 and 3 show particularly low near-surface $V_{S}$ values $(<100 \mathrm{~m} / \mathrm{s})$ with sharper shallow gradients. This is expected from the high-frequency content of the dispersion data for sites 2 and 3 (see Fig. 8), which show lower Rayleigh-wave phase velocities than at site 1. Geological mapping of the region suggests the three sites should be overlain by generally similar sandy-soil surficial material (Clague 1977, 1984).

Uncertainty in the $V_{S}$ profiles generally increases with depth at each site, as expected from the decaying resolution of dispersion data with depth. The estimated depth of the impedance contrast and the velocity in the half-space are not well-constrained. The MAP values $( \pm 1$ standard deviation) for the depth of a significant impedance contrast (called $z_{0}$ here) are 127 $\mathrm{m} \pm 26 \mathrm{~m}, 67 \mathrm{~m} \pm 11 \mathrm{~m}$, and $97 \mathrm{~m} \pm 24 \mathrm{~m}$ at sites 1, 2, and 3, respectively (Figs. 5(b), 6(b), and $7(\mathrm{~b}))$. The shallow $z_{0}$ depth at site 2 is expected from the dispersion data, which show a transition to higher phase velocities occurring at a higher frequency at site 2 , compared to sites 1 and 3 (see Fig. 8). The MAP values for the velocity in the half-space (sub-sediment material) are $1159 \mathrm{~m} / \mathrm{s} \pm 197 \mathrm{~m} / \mathrm{s}, 1049 \mathrm{~m} / \mathrm{s} \pm 168 \mathrm{~m} / \mathrm{s}$, and $1047 \mathrm{~m} / \mathrm{s} \pm 186 \mathrm{~m} / \mathrm{s}$ at sites 1,2 , and 3 , respectively. These velocities are consistent (within uncertainties) between sites. Similar uncertainties have been observed in other studies that considered Bayesian inversion of surface-wave dispersion data using power-law and uniform-layer (trans-dimensional) profile models in Molnar et al. (2010) and Dettmer et al. (2012), respectively.

Depending on the geological conditions, the depth resolution limit for dispersion data from passive array recordings is taken to be on the order of half the maximum resolvable wavelength (Park et al. 1999). Generally, the maximum resolvable wavelength is of the order of 3 times the maximum station separation distance, and the minimum resolvable wavelength is of the order of 2 times the mininum station separation distance (Tokimatsu 1997). In this case, the maximum and minimum station separation distances are $90 \mathrm{~m}$ and $5 \mathrm{~m}$, respectively, resulting in an approximate depth resolution of $135 \mathrm{~m}$. This is a possible explanation for the large 
uncertainties for $z_{0}$ estimated at sites 1 and 3 , where $z_{0}$ is potentially near the depth resolution limit of the data, compared to site 2 . In certain geological settings where sequences of constant lithology are much thicker than the depth resolution limit of passive dispersion data, a modelled impedance contrast (such as at $z_{0}$ ) may not represent a physical discontinuity to a homogeneous layer, but instead may mark the resolution limit of the dispersion data (e.g., Molnar et al. 2010; Dettmer et al. 2012). However, past drilling in the region suggest sediments of a similar thickness as estimated here (Dolmage 1956), and the agreement in half-space velocities between sites suggests the inversions do in fact resolve the physical base of the surficial sediments (albeit with significant uncertainties).

Fig. 5 also shows $V_{S}$ values computed from a nearby multi-component seismic-reflection survey (Pugin et al. 2017). The survey was conducted with 72 three-component geophones spaced $1.5 \mathrm{~m}$ apart with source-receiver offsets between 3 and $109.5 \mathrm{~m}$, and a source spacing of $4.5 \mathrm{~m}$. Shear-wave velocity values were computed at various discrete depths and at many common-mid-point (CMP) offsets along the seismic line. The values shown here are the mean velocity ( \pm 1 standard deviation) of all the computed CMP velocities along the seismic line, within 25 logarithmically-spaced depth intervals (similar to the procedure used by Molnar et al. (2010) for averaging SCPT and borehole data). The error bars provide a sense of the variability in the $V_{S}$ values from the seismic-reflection survey, as well as an approximate measure of the uncertainty due to lateral inhomogeneity. Both the processing of active-source reflection data as well as the inversion of passive-array dispersion data assume laterally homogeneous structure. Results from the seismic-reflection survey indicate horizontal reflectors with limited variability in depth along this profile. In contrast, the passive-array results represent an average solution over the spatial extent of the array, and lateral inhomogeneity may contribute to the estimated uncertainties in $V_{S}$ structure.

Results from passive-array dispersion data at site 1 are in relatively good agreement with the seismic-reflection survey results, particularly the trend in the $V_{S}$ profile between $20 \mathrm{~m}$ and 100 $m$ depth. The Vs estimates from noise inversion are slightly higher than those from reflection inversion over this depth range, but differences are within uncertainties of the two approaches. The significant deviation between the two results at depths $<10 \mathrm{~m}$ is most likely due to the fact that the reflection survey was conducted on a road surface as opposed to the open grass field 
where the passive array was installed. The road asphalt overlies hard, compacted gravels and road-construction materials that are expected to produce a high- $V_{S}$ signature to a depth of 3-5 $\mathrm{m}$, although deeper velocities are likely biased as a result. The depth at which the active-source results indicate the base of the sediments (approximately $110 \mathrm{~m}$ to $130 \mathrm{~m}$ ) is consistent with the depth estimated (with significant uncertainties) from the passive-array results. The results from the seismic-reflection survey indicate $z_{0}$ corresponds with a strong impedance contrast (bedrock or hard consolidated sediments), providing further evidence that inversion results at all Kitimat sites resolve the base of the surficial sediments. It should be noted that the $V_{S}$ values extracted from the reflection survey are along a single transect that is not co-located with the passive array (approximately $200 \mathrm{~m}$ north). Velocities calculated from seismic-reflection surveys have their own associated uncertainties (not quantified by Pugin et al. 2017) due to measurement errors and processing assumptions (e.g., homogeneous isotropic layers, flat horizontal reflectors, etc.), and are biased based on values estimated in the near-surface (Dix 1955; Pugin et al. 2009).

Fig. 8 shows the fit to the observed dispersion data at the three Kitimat sites (plotted as phase velocities, although slownesses were inverted). Inversion results at all sites show a good fit to the observed data with reasonable variance for the data predictions. The assumptions of the data error model within the inversion are validated by applying a posteriori statistical tests to the standardized residuals (differences between the observed and predicted data, divided by estimated standard deviations and accounting for the AR process) of the MAP model at each site. The Kolmogorov-Smirnov and runs tests were applied to quantitatively assess the validity of the assumptions of Gaussian-distributed, and random standardized residuals, respectively (Freund 1967; Dosso et al. 2006). These statistical tests indicate no significant evidence against the error assumptions.

\section{Seismic hazard site assessment}

Earthquake ground motions are influenced by the seismic source, the propagation path through the earth, and local sediment/soil conditions. This section considers local site-specific seismic hazards in terms of amplification due to $V_{S}$ profiles estimated from surface-wave dispersion data at the three Kitimat sites (similar to Molnar et al. 2013). This section does not consider amplification due to 3-D basin structure, or earthquake-specific rupture and propagation effects 
which are beyond the scope of this research. However, all of these factors are needed in order to predict the true ground motion during an earthquake.

The travel-time-weighted average of $V_{S}$ from the surface to a depth $z, V_{S Z}$, is calculated by

$$
V_{S Z}=\frac{z}{\int_{0}^{z} \frac{d z}{V_{S}(z)}} .
$$

Probability profiles for $V_{S Z}$ are calculated for the sampled PPD for each site (Figs. 9(a), 10(a), and 11(a)). Complicated structure in the $V_{S Z}$ profile can suggest average- $V_{S}$-based classification schemes and amplification predictions are not suitable. Specifically, if large near-surface $V_{S}$ discontinuities exist (that would significantly affect seismic amplification and resonance), the arbitrary choice of $30 \mathrm{~m}$ for seismic hazard classification would not be justified. This is specifically why the lower prior bound on the depth of the base of the sediments $z_{0}$ was set shallower than $30 \mathrm{~m}$. Surface-wave dispersion data do not generally resolve detailed structure beyond a significant impedance contrast such as the sediment-basement boundary (Wathelet et al. 2008). If such a boundary existed in the upper $30 \mathrm{~m}$, the data would have required $z_{0}$ to be shallow. However, the $V_{S Z}$ marginal profiles at the three Kitimat sites show smooth nearsurface structure, and $V_{S 30}$ is believed to be a reasonable proxy for site amplification here. As such, $V_{S 30}$-dependent site classification and amplification predictions should provide meaningful information. Distributions of $V_{S 30}$ indicate that site classification D (stiff soil), adopted by the National Building Code of Canada, is representative of each site (Figs. 9(b), 10(b), and 11(b)). The probabilities for site classification $\mathrm{C}, \mathrm{D}$, and $\mathrm{E}$ at each site are shown as percentages in Figs. 9(b), 10(b), and 11(b)).

Recent GMMs use $V_{S 30}$ as a convenient parameter (representative of soil/sediment rigidity conditions) to calculate site amplification. Seyhan and Stewart (2014) developed a model for the site amplification term in the Boore et al. (2014) GMM using a combination of empirical ground-motion observations and ground-motion simulations. The model describes groundmotion scaling with $V_{S 30}$ as well as nonlinear soil effects. The nonlinear response of soil/sediment is due to the reduction in shear strength (and increased damping) as shear strain increases, and modifies the frequency-dependent response of site amplification (Hardin and Drnevich 1973). Including nonlinear effects requires knowledge of earthquake and propagation-path properties. 
Nonlinear effects generally decreases site amplification predictions and are not included here to provide conservative estimates of site amplification factors, and eliminate the requirement of predictions for earthquake-specific scenarios. The linear site amplification term $F_{\text {lin }}$ is calculated according to

$$
\log _{e}\left(F_{\text {lin }}\right)=\left\{\begin{array}{cc}
b \log _{e}\left(\frac{V_{S 30}}{V_{\text {ref }}}\right) & V_{S 30} \leq V_{b} \\
b \log _{e}\left(\frac{V_{b}}{V_{\text {ref }}}\right) & V_{S 30}>V_{b}
\end{array},\right.
$$

where $b$ is a coefficient describing the linear $V_{S 30}$ scaling, $V_{b}$ is the velocity at which site amplification no longer scales with $V_{S 30}$, and $V_{r e f}$ is the $V_{S 30}$ value for a reference (hard ground) site where amplification is unity, taken to be $760 \mathrm{~m} / \mathrm{s}$ as prescribed by Seyhan and Stewart (2014) and Boore et al. (2014). The use of $760 \mathrm{~m} / \mathrm{s}$ for $V_{\text {ref }}$ also provides conservative amplification estimates within Canada as the National Building Code of Canada uses site class C as a reference site (Table 1), and $760 \mathrm{~m} / \mathrm{s}$ is the upper bound of the $V_{S 30}$ range for this site class (Adams et al. 2015; Humar 2015). The coefficients $V_{b}$ and $b$ are included within a software routine by Seyhan and Stewart (2014).

Site amplification factors are computed for peak ground velocity (PGV), peak ground acceleration (PGA), and spectral acceleration (SA) response at periods of engineering interest using the $V_{S 30}$ probability densities for Kitimat sites 1, 2, and 3 (Figs. 9, 10, and 11, respectively). The SA response describes the maximum acceleration of a damped harmonic oscillator (with a specific natural frequency) with a single degree of freedom. This SA response generally provides a more complete prediction of the motion of a structure during an earthquake than simply PGA or PGV (e.g., Adams et al. 2015). Mean amplification factors and uncertainties ( \pm 1 standard deviation) for PGV, PGA and SA (at 2 s period) are summarized in Table 3. As is expected, the higher near-surface $V_{S}$ values at site 2 result in higher $V_{S 30}$ estimates and, consequently, smaller amplification predictions than at the other two sites.

Amplification and resonance of $S_{H}$ waves are considered using ground-motion simulation software developed by Boore (2005). This routine assumes the earth-structure model is composed of a stack of homogeneous layers of differing geophysical parameters (layer thickness, $V_{S}$, density, and quality factor $Q$ ) and uses the Thomson-Haskell method to calculate the transfer function of a vertically-incident plane $S_{H}$ wave. Density and $V_{P} / V_{S}$ values were not well constrained within the inversion. As a result, density values used to compute $S_{H}$ wave am- 
plification and resonance are calculated using an empirical relationship (Brocher 2005). The quality factor $Q$ (which accounts for attenuation) is drawn from a Gaussian distribution with mean 20 and standard deviation 10 (with an imposed lower bound of 2). This is believed to be representative of the sediments in Kitimat and consistent with previous studies that simulated amplification and resonance of $S_{H}$ waves in Holocene deltaic sediments (Brocher 2008; Molnar et al. 2013). Fig. 12 shows probability densities for predicted $S_{H \text {-wave amplification }}$ at the three sites in Kitimat. The mean ( \pm 1 standard deviation) for fundamental resonance frequency $f_{S H}$, and amplification $\left(\right.$ at $f_{S H}$ ) for each site are listed in Table 3 . These frequencies are directly related to the estimated depth of the base of the sediments. At site 2, where this transition occurs at the shallower depth, resonance occurs at a higher frequency. Higher-order resonant frequencies are not well determined due to the large uncertainties in the estimated depth and velocity of underlying material. The level of amplification at high frequencies is lower at site 1 than at sites 2 and 3 due to the higher near-surface $V_{S}$ values estimated at this site. The highest amplification is estimated at site 2. This is likely due to the combined effects of low near-surface $V_{S}$ values and a relatively-shallow sediment base, compared to sites 1 and 3. The relatively large uncertainties in estimated amplification (at $f_{S H}$ ) are likely due to the large uncertainty in the estimated velocity of the material underlying surficial sediments, since it is this main impedance contrast which produces fundamental resonance and amplification. Knowledge of the resonance frequencies at these sites has practical uses in engineering and design.

\section{Conclusions}

This work considered the collection, processing and inversion of passive seismic array recordings collected at three sites in Kitimat, BC. The data were inverted within a Bayesian (probabilistic) framework using a general and efficient approach to parameterizing smooth gradient-based $V_{S}$ profiles in terms of a Bernstein-polynomial representation. A MCMC method was used to sample the PPD of the model parameters, and the results are represented by $V_{S}$ marginal probability profiles at each site. Inversion results are relatively consistent between sites, and are in good agreement with past drilling in the region as well as $V_{S}$ estimates from a nearby activesource seismic-reflection survey. In particular, the active-source survey indicates a transition 
to high-velocity material beneath the surficial sediments at a similar depth to that estimated from the passive-array method.

The inversion results were used to calculate marginal probability profiles of $V_{S Z}\left(V_{S}\right.$ averaged to depth $z$ ) at every site, as well as probability distributions of $V_{S 30}$. The $V_{S 30}$ values indicate that site classification D (stiff soil), according to the National Building Code of Canada, is representative of all sites (with a high degree of certainty). Linear site amplification terms (that are $V_{S 30^{-}}$dependent) were computed for PGV, PGA, and SA using a semi-empirical model and indicate site amplification factors of 2.4-3.0 for PGV, and 1.8-2.2 for PGA. The amplification and resonance of $S_{H}$ waves were estimated using the full $V_{S}$ marginal density profiles and provided estimates of fundamental resonance frequencies of 1.1-1.5 Hz and amplification factors at the fundamental frequency of 2.9-3.6.

One of the sites considered in this study is co-located with a recently-deployed soil seismographic monitoring station that is currently recording ground motions as part of a 5-year campaign. The $V_{S}$ structure and site response estimated in this work will be useful for future seismological research in the region. Specifically, site corrections derived from the $V_{S}$ structure estimated in this study will be applied to on-going measurements from this new soil station. In addition, site assessment estimates presented here may provide a baseline for comparison with future empirical site assessment studies in Kitimat. The findings presented here are the first robust, probabilistic estimates of $V_{S}$ structure and site response in Kititmat, BC, and should ultimately be useful for engineers, planners, and regulatory agencies to mitigate the hazard of seismic amplification and resonance. Lastly, as Kitimat is characteristic of typical fjord systems along the $\mathrm{BC}$ coast, the results from this work may be useful for other coastal communities in BC.

\section{Acknowledgments}

This work was supported by the Natural Sciences and Engineering Research Council of Canada (NSERC) and the University of Victoria. The authors thank Heather Crow, André Pugin, Didier Perret, and Barbara Dietiker for useful discussions on the active-source experiment discussed here, as well as other site assessment studies conducted in Canada. The authors also thank Dan Perera for building the portable seismometer array used in this work. The compu- 
tational work was carried out on a parallel high-performance computing cluster operated by the authors at the University of Victoria funded by NSERC, the Strategic Environmental Research and Development program, and the Office of Naval Research. This is Natural Resources Canada Contribution Number 20170045.

\section{References}

Adams, J., Halchuk, S., Allen, T., and Rogers, G.C. 2015. Canada 5th generation seismic hazard model, as prepared for the 2015 National Building Code of Canada. Proceedings of The 11th Canadian Conference on Earthquake Engineering, victoria, Canada.

Aki, K. 1957. Space and time spectra of stationary stochastic waves, with special reference to microtremors. Bulletin of the Earthquake Research Institute, 35:415-456.

Anderson, J.G., Bodin, P., Brune, J.N., Prince, J., Singh, S.K., Quass, R., and Onate, M. 1986. Strong motion from the Michoacan, Mexico, earthquake. Science, 233:1043-1049.

Anderson, J.G., Lee, Y., Zeng, Y., and Day, S. 1996. Control of strong motion by the upper 30 meters. Bulletin of the Seismological Society of America, 86:1749-1759.

Bard, P.Y., and Bouchon, M. 1980. The two-dimensional resonance of sediment-filled valleys. Bulletin of the Seismological Society of America, 75:519-541.

Boore, D.M. 2005. SMSIM FORTRAN programs for simulating ground motions from earthquakes: Version 2.3. USGS open file report, 96-80-A, Online Manual, www.daveboore.com.

Boore, D.M., and Atkinson, G.M. 2008. Ground-motion prediction equations for the average horizontal component of PGA, PGV, and 5 percent damped PSA at spectral periods between $0.01 \mathrm{~s}$ and $10.0 \mathrm{~s}$. Earthquake Spectra, 24:99-138.

Boore, D.M., Stewart, J.P., Seyhan, E., and Atkinson, G.M. 2014. NGA-West2 equations for predicting PGA, PGV, and 5 percent damped PSA for shallow crustal earthquakes. Earthquake Spectra, 30:1057-1085.

Borcherdt, R.D. 1994. Estimates of site-dependent response spectra for design (methodology and justification). Earthquake Spectra, 10:617-653. 
Bornhold, B.D. 1983. Sedimentation in Douglas Channel and Kitimat Arm. Canadian Technical Report of Hydrography and Ocean Sciences, 18:88-114.

Bostwick, T.K. 1984. A re-examination of the August 22, 1949 Queen Charlotte earthquake. Master's thesis, University of British Columbia, British Columbia, Canada.

Brillon, C. 2016a. Baseline assessment of seismic hazard in British Columbia's north coast. Technical Report Open File 7994, Geological Survey of Canada.

Brillon, C. 2016b. North Coast geohazards - 2016 seismology update. Technical Report Open File 8052, Geological Survey of Canada.

Brillon, C., Cote, M.M., and Hunter, J.A. 2015. HVSR analysis of preliminary Kitimat ambient noise survey. Technical Report Open File 7793, Geological Survey of Canada.

Brocher, T.M. 2005. Empirical relations between elastic wavespeeds and density in the earth's crust. Bulletin of the Seismological Society of America, 95:2081-2092.

Brocher, T.M. 2008. Compressional and shear-wave velocity versus depth relations for common rock types in northern California. Bulletin of the Seismological Society of America, 98:950968.

Brooks, S., Gelman, A., Jones, G., and Meng, X.L. 2011. Handbook of Markov Chain Monte Carlo. CRC press.

Cassidy, J.F., Rogers, G.C., and Hyndman, R.D. 2014. An overview of the 28 October 2012 M 7.7 earthquake in Haida Gwaii, Canada: A tsunamigenic thrust event along a predominantly strike-slip margin. Pure and Applied Geophysics, 171:3457-3457.

Castellaro, S., Mulargia, F., and Rossi, P.L. 2008. VS30: Proxy for seismic amplification. Seismological Research Letters, 79:540-543.

Clague, J. 1984. Deglaciation of Prince Rupert - Kitimat area, British Columbia. Canadian Journal of Earth Sciences, 22:256-265.

Clague, J.J. 1977. Surficial geology, Kitimat, British Columbia. Technical Report Open File 470, Geological Survey of Canada. 
Conway, K.W., Barrie, J.V., and Thomson, R.E. 2012. Submarine slope failures and tsunami hazard in coastal British Columbia: Douglas Channel and Kitimat Arm. Technical Report Current Research 2012-10, Geological Survey of Canada.

Crow, H.L., Hunter, J., Brewer, K., Brillon, C., Cote, M., Allen, T., Cassidy, J.F., and Hayek, S. 2015. Soft soil response investigations in Kitimat, BC: some preliminary results. Proceedings of The 11th Canadian Conference on Earthquake Engineering, victoria, Canada.

Dettmer, J., Molnar, S., Steininger, G., Dosso, S.E., and Cassidy, J.F. 2012. Trans-dimensional inversion of microtremor array dispersion data with hierarchical autoregressive error models. Geophysical Journal International, 188:719-734.

Dix, C.H. 1955. Seismic velocities from surface measurements. Geophysics, 20:68-86.

Dolmage, V. 1956. Geology of Kitimat area in British Columbia. Report to the Township of Kitimat, 1956, 29p.

Dosso, S.E., Nielsen, P.L., and Wilmut, M.W. 2006. Data error covariance in matched-field inversion. Journal of the Acoustical Society of America, 119:208-219.

Dosso, S.E., and Wilmut, M.J. 2006. Data uncertainty estimation in matched-field geoacoustic inversion. Journal of Ocean Engineering, 31:470-479.

FEMA Provision 750 2009. NEHRP (national earthquake hazards reduction program) recommended seismic provisions for new buildings and other structures. Building Seismic Safety Council, Washington, DC, 406.

Finn, W.D.L., and Wightman, A. 2003. Ground motion amplification factors for the proposed 2005 edition of the National Building Code of Canada. Canadian Journal of Civil Engineering, 30:272-278.

Freund, J.E. 1967. Modern Elementary Statistics. Prentice-Hall, Englewood Cliffs, NJ.

Gardner, G.H.F., Gardner, L.W., and Gregory, A.R. 1974. Formation velocity and density: The diagnostic basics for stratigraphic traps. Geophysics, 39:770-780. 
Gosselin, J.M., Dosso, S.E., Cassidy, J.F., Quijano, J.E., Molnar, S., and Dettmer, J. 2017. A gradient-based model parameterization using bernstein polynomials in bayesian inversion of surface-wave dispersion. Geophysical Journal International.

Graves, R.W., Pitarka, A., and Sommerville, P. 1998. Ground-motion amplification in the Santa Monica area: Effects of shallow basin-edge structure. Bulletin of the Seismological Society of America, 88:1224-1242.

Hardin, B.O., and Drnevich, V.P. 1973. Shear modulus and damping in soils. Journal of the Soil Mechanics and Foundations Division, 99:849-862.

Hastings, W.K. 1970. Monte Carlo sampling methods using Markov chains and their applications. Biometrika, 57:97-109.

Humar, J. 2015. Background to some of the seismic design provisions of the 2015 National Building Code of Canada. Canadian Journal of Civil Engineering, 42:940-952.

Kass, R.E., and Raftery, A.E. 1995. Bayes factors. Journal of the American Statistical Association, 90:773-795.

KITI-MAP 2016. KITI-MAP GIS Webmapping. Municipal District of Kitimat, www.kitimat.ca.

Lacoss, R.T., Kelly, E.J., and Toksoz, M.N. 1969. Estimation of seismic noise structure using arrays. Geophysics, 34:21-38.

Lee, V.W., and Trifunac, M.D. 2010. Should average shear-wave velocity in the top 30m of soil be used to describe seismic amplification? Soil Dynamics and Earthquake Engineering, 30:1250-1258.

Metropolis, N., Rosenbluth, A., Rosenbluth, M., and Teller, A.T.A.E. 1953. Equations of state calculations by fast computing machines. Journal of Chemical Physics, 21:1087-1092.

Molnar, S., Cassidy, J.F., and Dosso, S.E. 2013. Uncertainty of linear earthquake site amplification via Bayesian inversion of surface seismic data. Geophysics, 78:WB37-WB48.

Molnar, S., Dosso, S.E., and Cassidy, J.F. 2010. Bayesian inversion of microtremor array dispersion data in southwestern British Columbia. Geophysical Journal International, 183:923-940. 
Mosegaard, K., and Tarantola, A. 1995. Monte Carlo sampling of solutions to inverse problems. Journal of Geophysical Research, 100:12431-12447.

NBCC 2010. National Building Code of Canada 2010. Institute for Researchin Construction, National Research Council of Canada.

Park, C.B., Miller, R.D., and Xia, J. 1999. Multichannel analysis of surface waves. Geophysics, 64:800-808.

Pugin, A.J.M., Crow, H., Dietiker, B., Brewer, K., Cartwright, T., Brillon, C., Hunter, J.A., Gosselin, J., and Allen, T. 2017. Soft soil response investigations in Kitimat, BC: Geophysical data sets. Technical Report Open File, in prep., Geological Survey of Canada.

Pugin, A.J.M., Pullan, S.E., and Hunter, J.A. 2009. Multicomponent high-resolution seismic reflection profiling. The Leading Edge, 28:1248-1261.

Pugin, A.M., Brewer, K., Cartwright, T., Pullan, S.E., Perret, D., Crow, H., and Hunter, J.A. 2013. Near surface s-wave seismic reflection profiling: New approaches and insights. First Break, 31:49-60.

Quijano, J.E., Dosso, S.E., Dettmer, J., and Holland, C.W. 2016. Geoacoustic inversion for the seabed transition layer using a Bernstein polynomial model. Journal of the Acoustical Society of America, in review.

Schwartz, G. 1978. Estimating the dimensions of a model. Annals of Statistics, 6:461-464.

Seyhan, E., and Stewart, J.P. 2014. Semi-empirical nonlinear site amplification from NGAWest2 data and simulations. Earthquake Spectra, 30:1241-1256.

Shumway, R., and Stoffer, D. 2000. Time Series Analysis and Its Applications. Springer, New York, NY.

Tokimatsu, K. 1997. Geotechnical site characterization using surface waves. Proceedings 1st International Conference on Earthquake Geotechnical Engineering:Balkema, pp. 13331368.

Wathelet, M. 2005. Array recordings of ambient vibrations: surface-wave inversion. Ph.D. thesis, University of Liege, Wallonia, Belgium. 
${ }_{590}$ Wathelet, M., Jongmans, D., Ohrnberger, M., and Bonnefoy-Claudet, S. 2008. Array perfor591 mances for ambient vibrations on a shallow structure and consequences over VS inversion. 592 Journal of Seismology, 12:1-19. 


\section{${ }_{593}$ Tables}

Table 1: $V_{S 30}$ site classification used in 2015 National Building Code of Canada.

\begin{tabular}{lll}
\hline Site classification & Description & $V_{S 30}$ range $(\mathrm{m} / \mathrm{s})$ \\
\hline A & Hard rock & $>1500$ \\
B & Rock & $760-1500$ \\
C & Very dense soil and soft rock & $360-760$ \\
D & Stiff soil & $180-360$ \\
E & Soil with soft clay & $<180$ \\
F & Site-specific analysis required \\
\hline
\end{tabular}


Table 2: Prior bounds for model parameters in inversion of Kitimat dispersion data.

\begin{tabular}{ccc}
\hline Parameter & $\min$ & $\max$ \\
\hline & & \\
$V_{S}$ Bernstein-polynomial coefficients $(\mathrm{m} / \mathrm{s})$ & 50 & 800 \\
$V_{P} / V_{S}$ Bernstein-polynomial coefficients & 1.4 & 3 \\
Half-space transition depth $z_{0}(\mathrm{~m})$ & 20 & 150 \\
Half-space $V_{S}(\mathrm{~m} / \mathrm{s})$ & 500 & 1500 \\
Half-space $V_{P} / V_{S}$ & 1.4 & 3 \\
AR data-error coefficient & 0 & 0.9 \\
\hline
\end{tabular}


Table 3: Summary of estimated amplification factors at all Kitimat sites.

\begin{tabular}{cccccc}
\hline Kitimat site & PGV & PGA & SA $(2 \mathrm{~s})$ & $f_{S H}(\mathrm{~Hz})$ & $S_{H}$ Amplification \\
\hline & & & & & \\
1 & $2.4 \pm 0.20$ & $1.8 \pm 0.11$ & $1.8 \pm 0.13$ & $1.1 \pm 0.26$ & $2.9 \pm 0.62$ \\
2 & $2.7 \pm 0.18$ & $2.0 \pm 0.10$ & $1.9 \pm 0.08$ & $1.5 \pm 0.23$ & $3.6 \pm 0.72$ \\
3 & $3.0 \pm 0.23$ & $2.2 \pm 0.12$ & $2.1 \pm 0.10$ & $1.2 \pm 0.26$ & $3.5 \pm 0.75$ \\
\hline
\end{tabular}


${ }_{594}$ Figures

Figure 1: Location of Kitimat, BC, Canada.

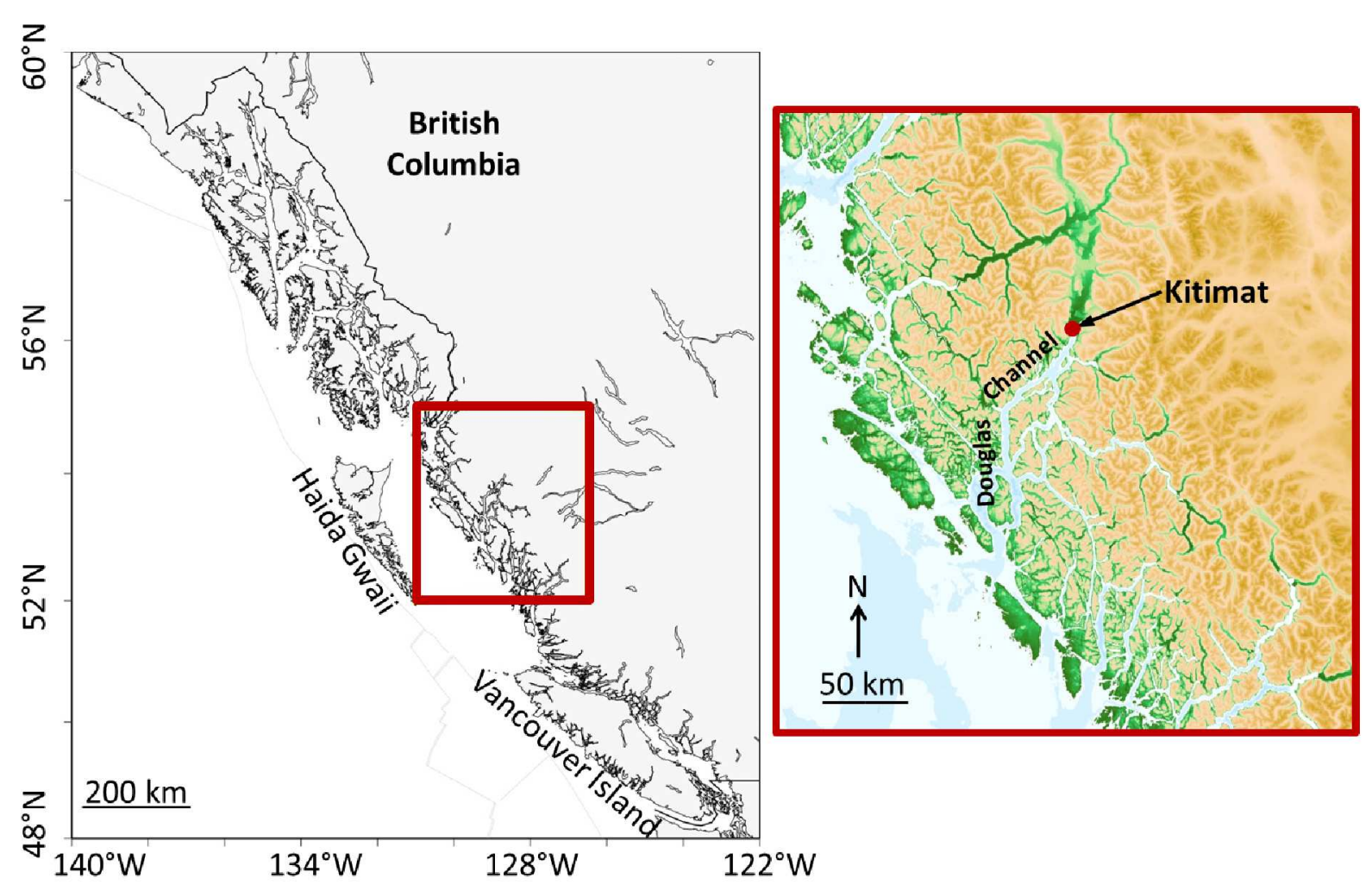


Figure 2: Locations of the three array sites in Kitimat, BC (air photo downloaded from KITIMAP 2016). The red line north of site 1 shows the location of the seismic-reflection survey from Pugin et al. (2017) used for comparison to inversion results.

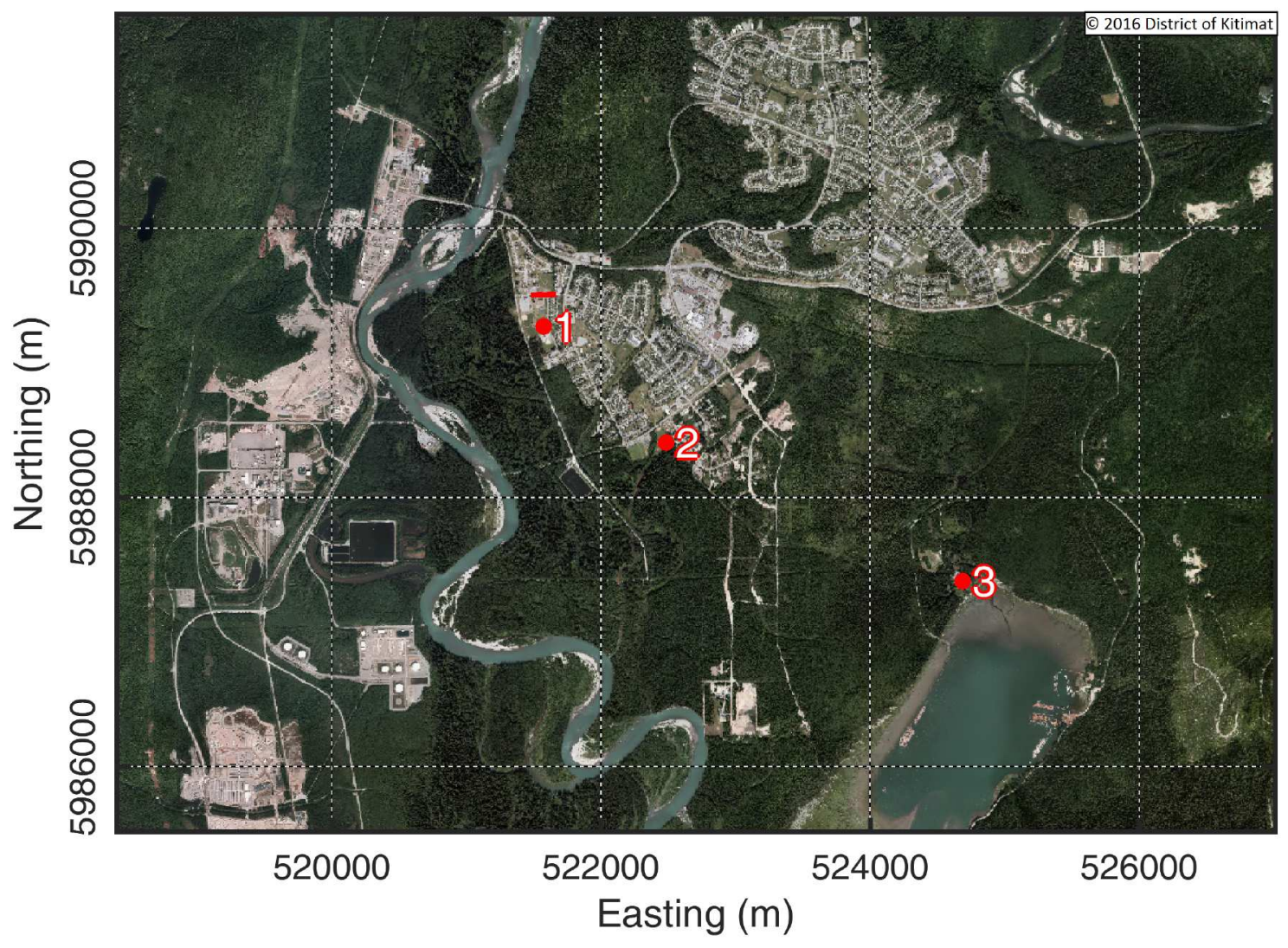


Figure 3: Seismic station installation including: three-component broadband seismometer (a), digitizer and recorder (b), and GPS antenna (c).

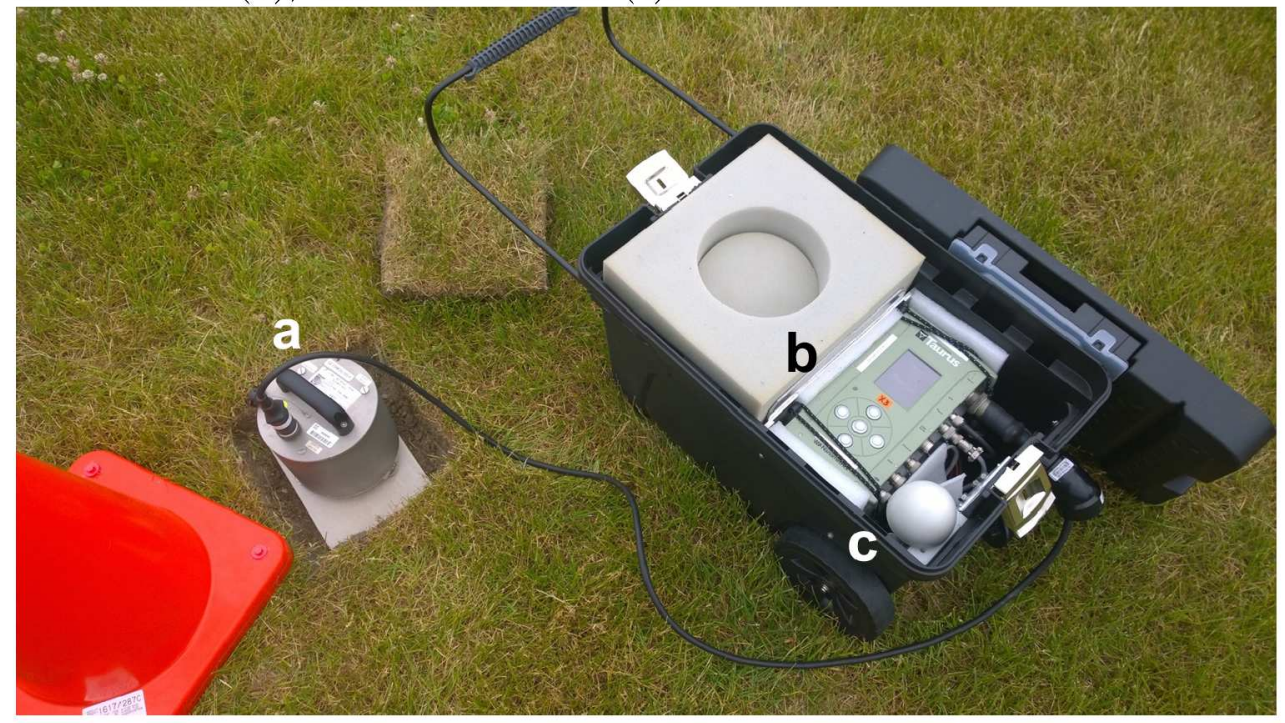


Figure 4: (a) Processed dispersion data (with 1 standard deviation error bars from $f$ - $k$ processing), and (b) array configurations with corresponding colours, at Kitimat site 1 (air photo downloaded from KITI-MAP 2016). The red line shows the location of the active-source seismicreflection survey from Pugin et al. (2017) used for comparison to site 1 results.
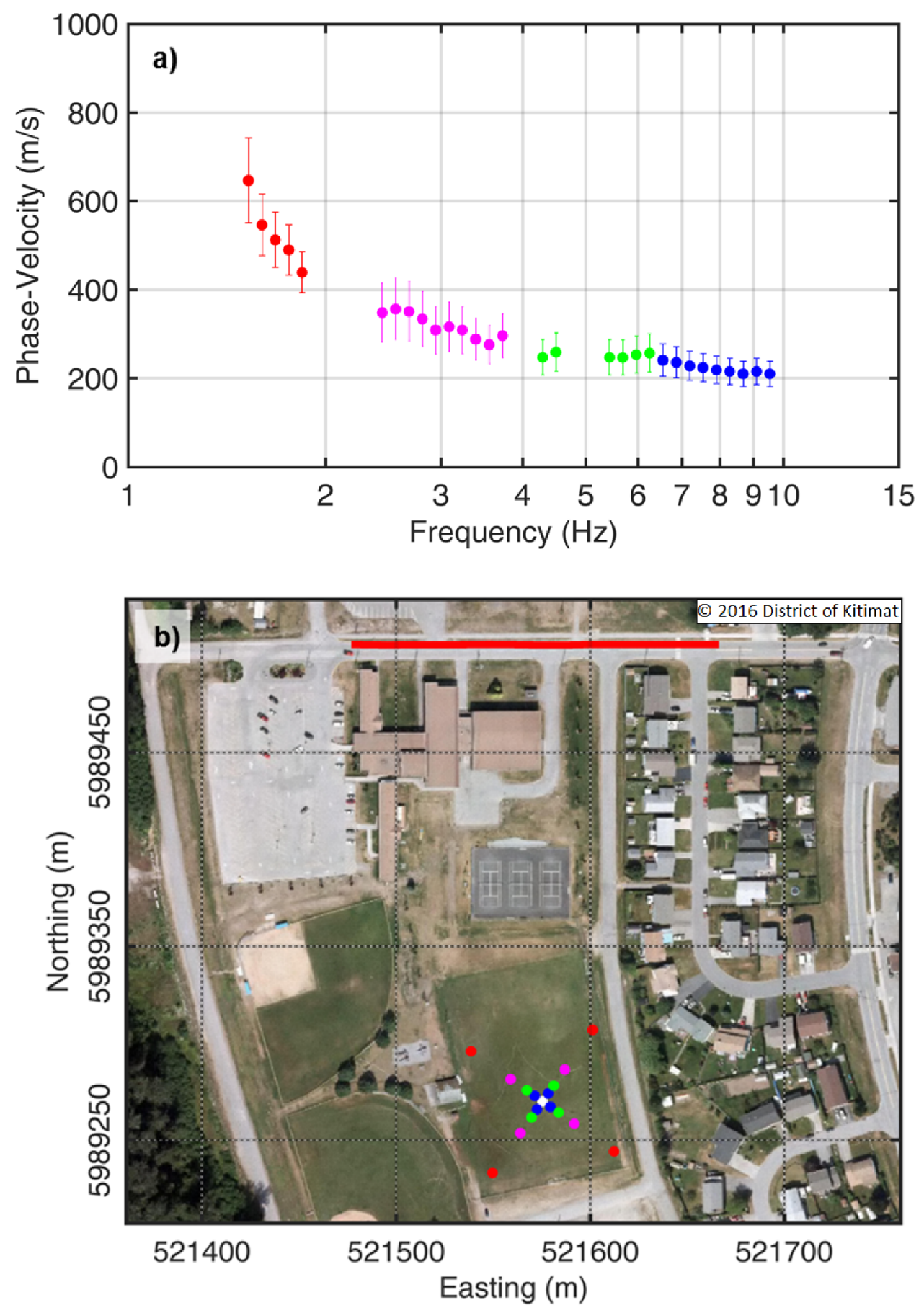
Figure 5: (a) Marginal probability profile for $V_{S}$, and (b) marginal probability density of halfspace transition depth $z_{0}$ at Kitmat site 1 . In (a), probabilities are normalized independently at every depth for display purposes. Warm colours (red) in (a) represent high probability and cool colours (blue) represent low probability. The white dots in (a) indicate mean values (with 1 standard deviation error bars ) representing the range of velocities calculated at the same depths along the nearby seismic-reflection survey from Pugin et al. (2017).
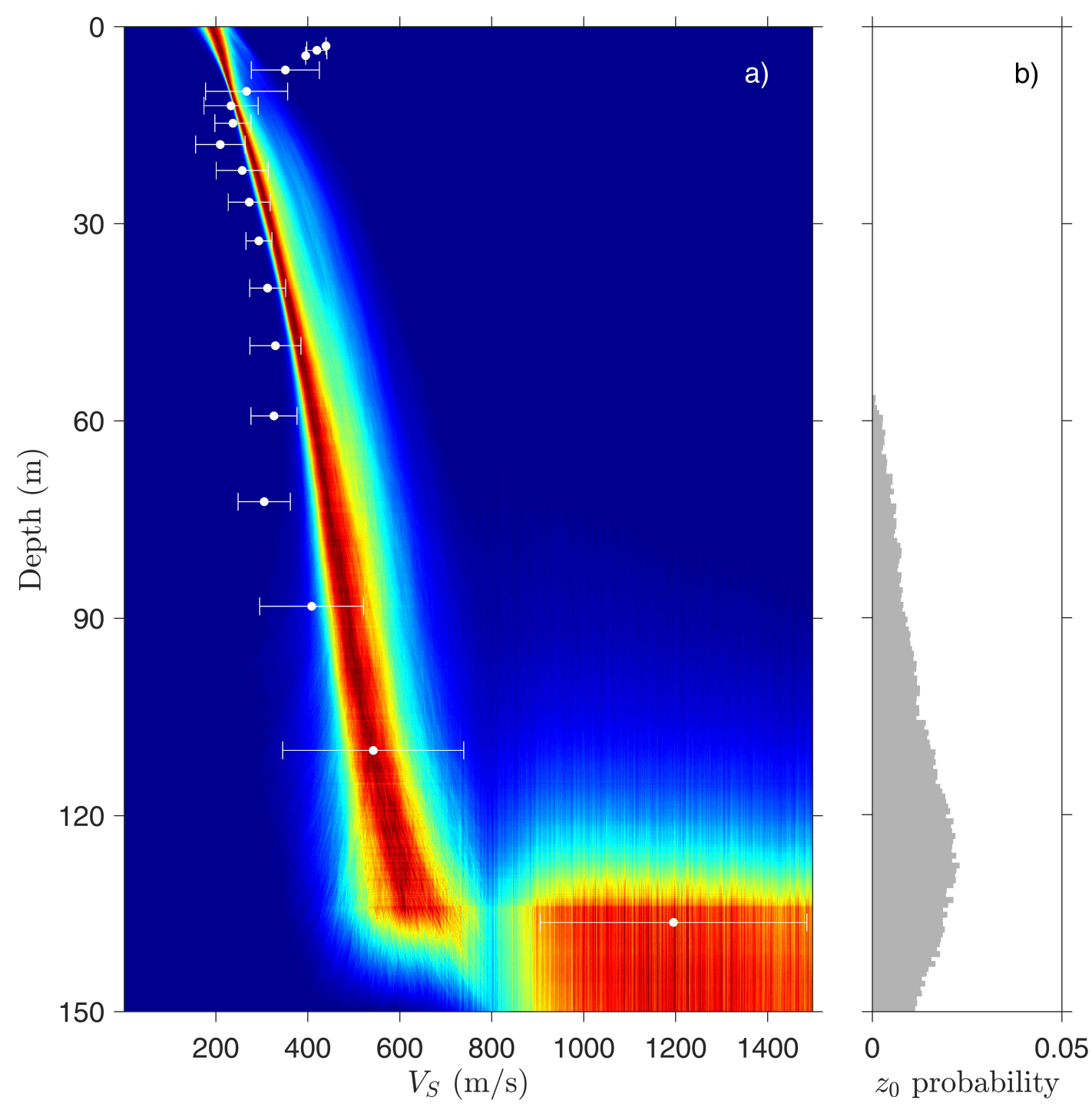
Figure 6: (a) Marginal probability profile for $V_{S}$, and (b) marginal probability density of halfspace transition depth $z_{0}$ at Kitmat site 2 .
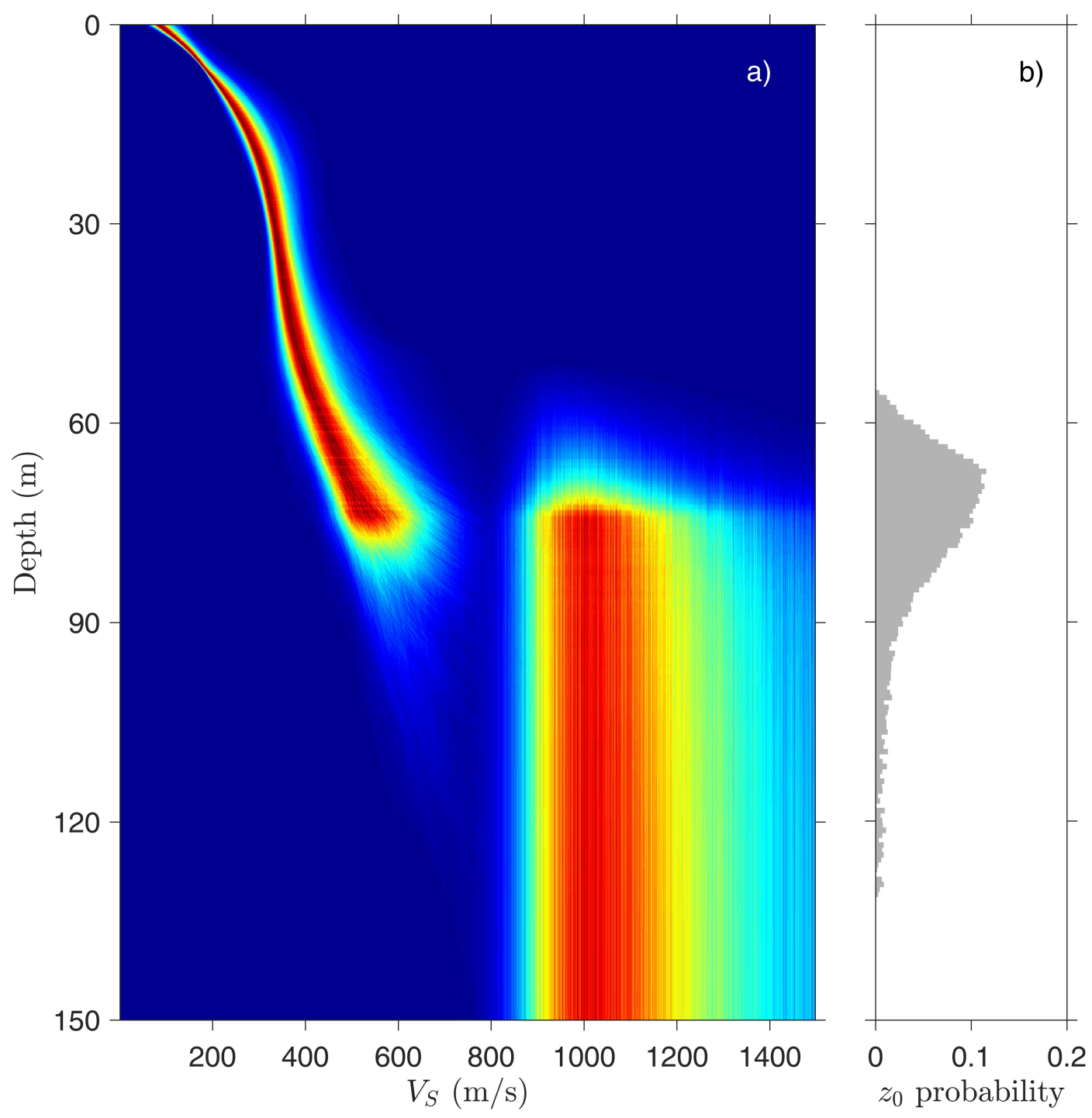
Figure 7: (a) Marginal probability profile for $V_{S}$, and (b) marginal probability density of halfspace transition depth $z_{0}$ at Kitmat site 3 .
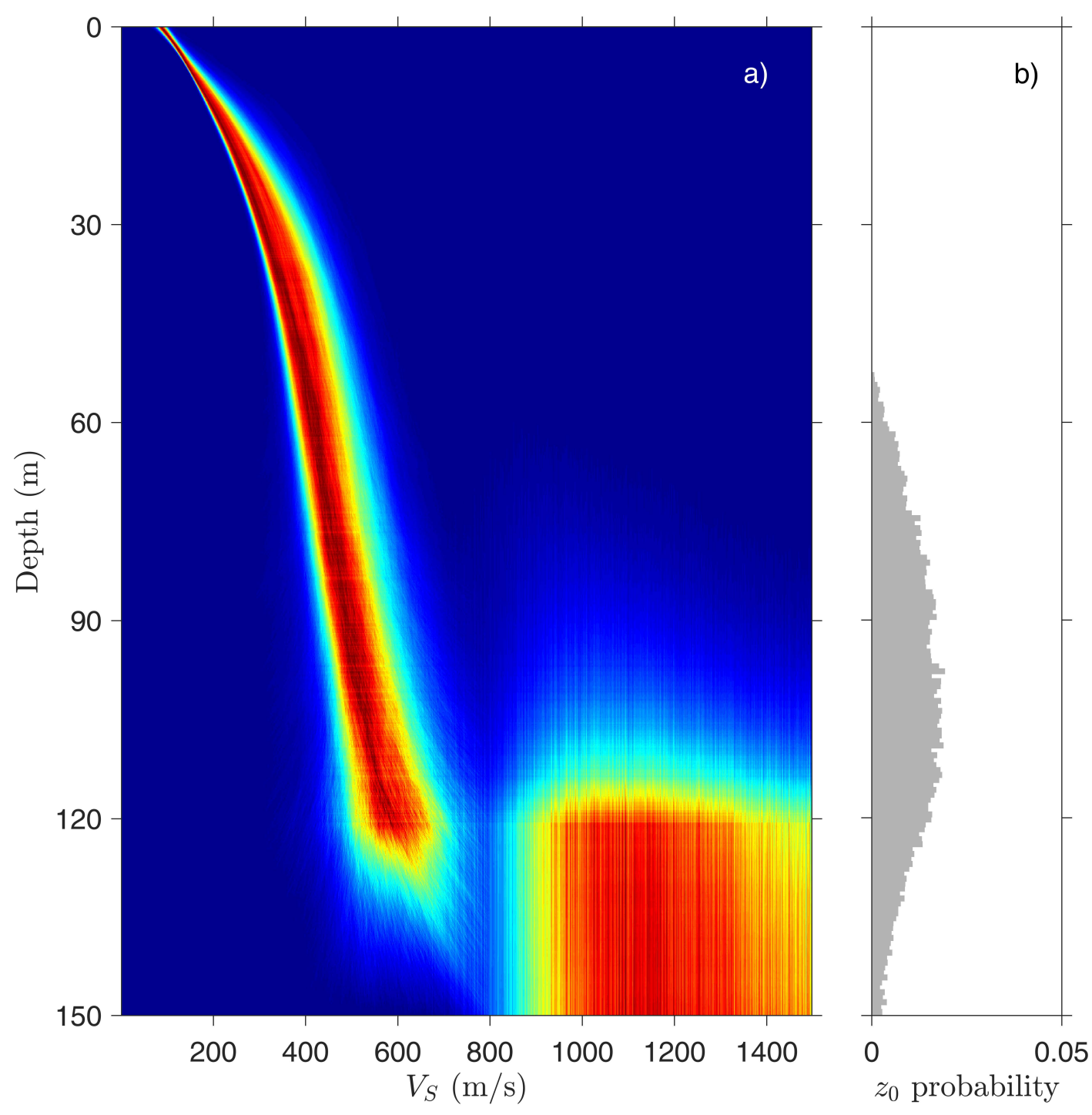
Figure 8: Data fit to dispersion data from Kitimat sites 1, 2, and 3 in (a), (b), and (c), respectively. The red stars are the observed dispersion data, and the blue dots with error bars are the mean predicted data (with 2 standard deviation error bars) from the MCMC samples.
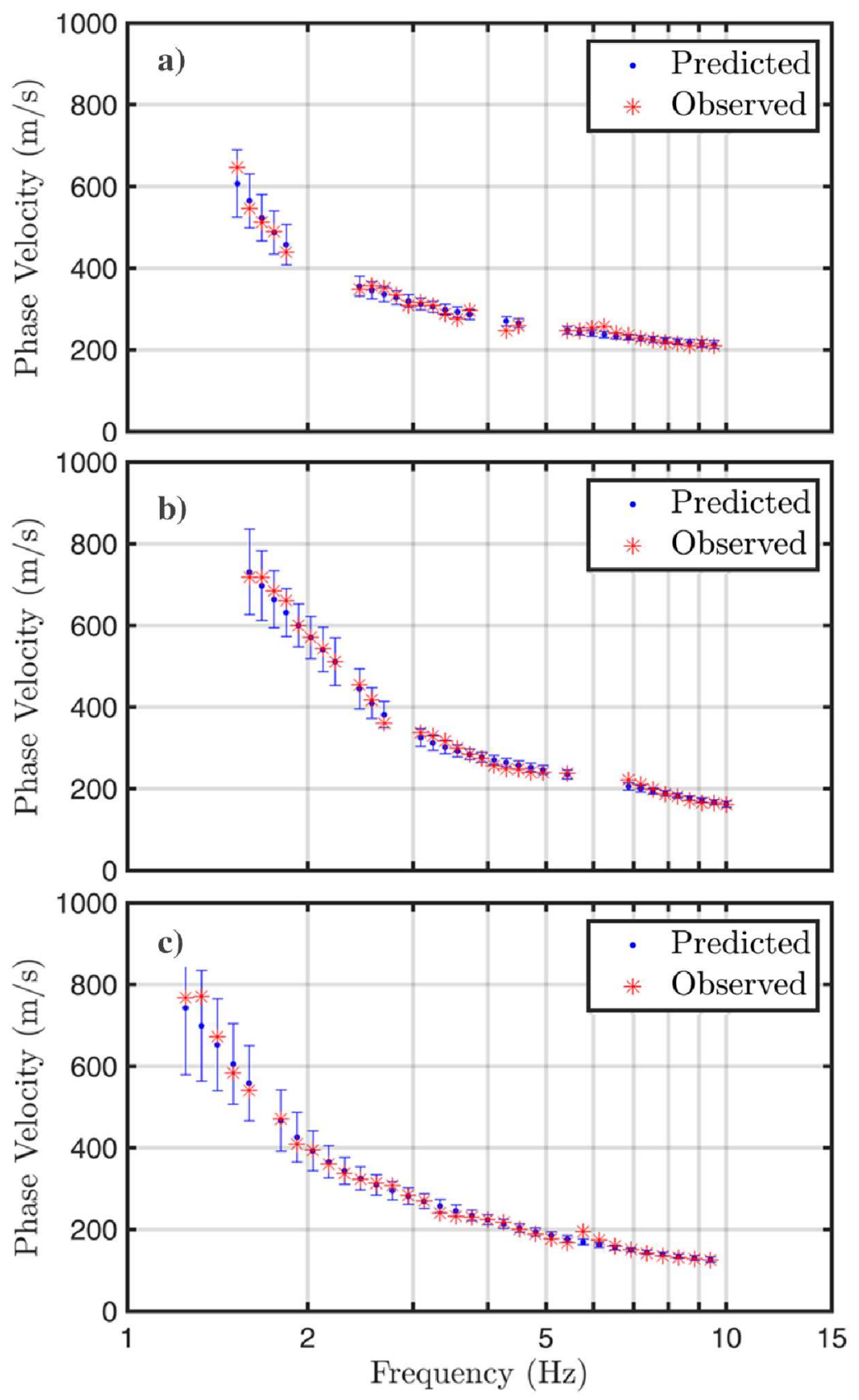
Figure 9: (a) $V_{S Z}$ probability density profile, (b) $V_{S 30}$ distribution, and $V_{S 30}$-dependent amplification factors for (c) PGV, (d) PGA, and (e) SA at Kitimat site 1. $V_{S 30}$ site classification boundaries (and probabilities) are shown in (b). The dashed line in (a) marks $30 \mathrm{~m}$ depth (i.e., delineates Vs30).
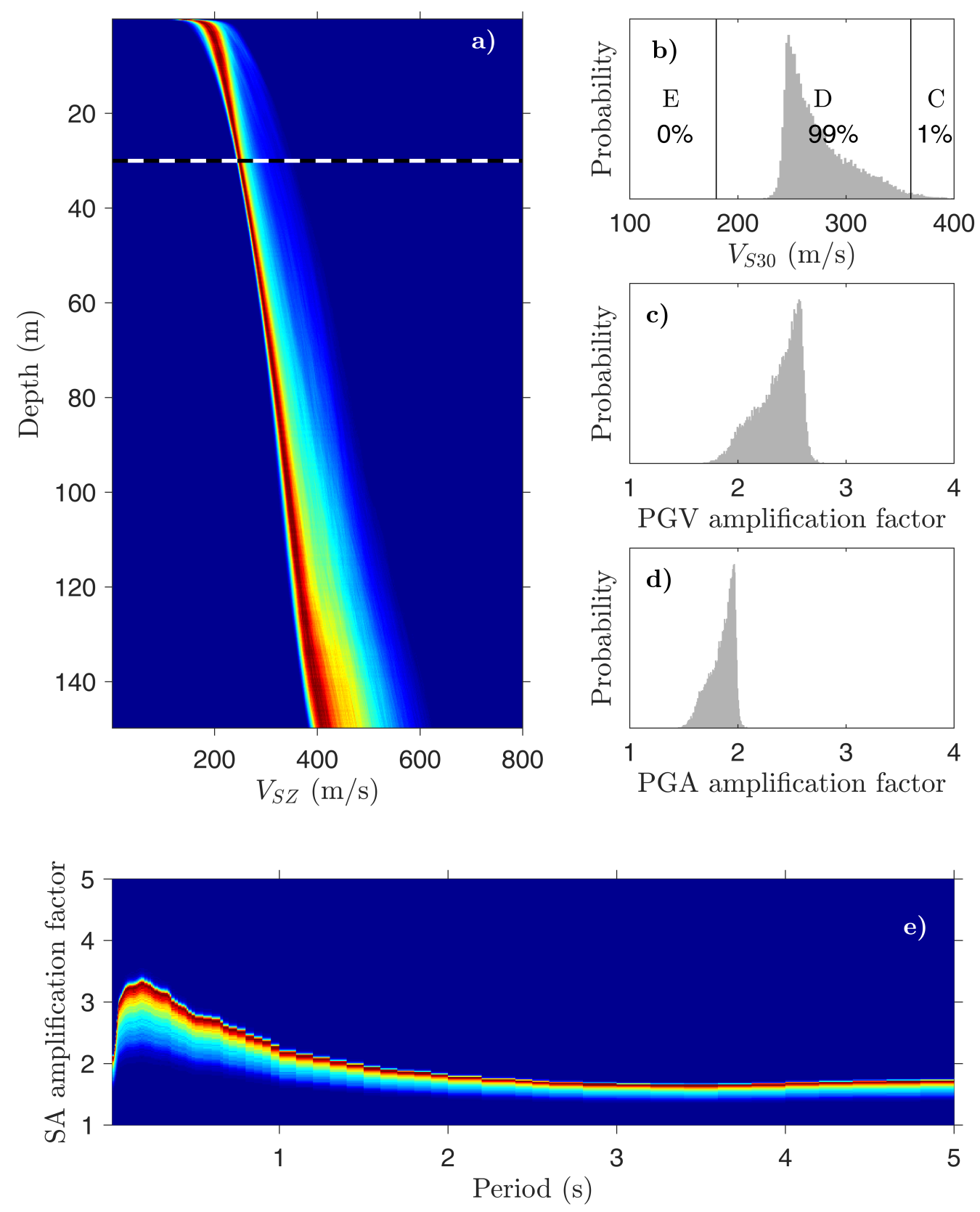
Figure 10: (a) $V_{S Z}$ probability density profile, (b) $V_{S 30}$ distribution, and $V_{S 30}$-dependent amplification factors for (c) PGV, (d) PGA, and (e) SA at Kitimat site 2. $V_{S 30}$ site classification boundaries (and probabilities) are shown in (b). The dashed line in (a) marks $30 \mathrm{~m}$ depth (i.e., delineates Vs30).
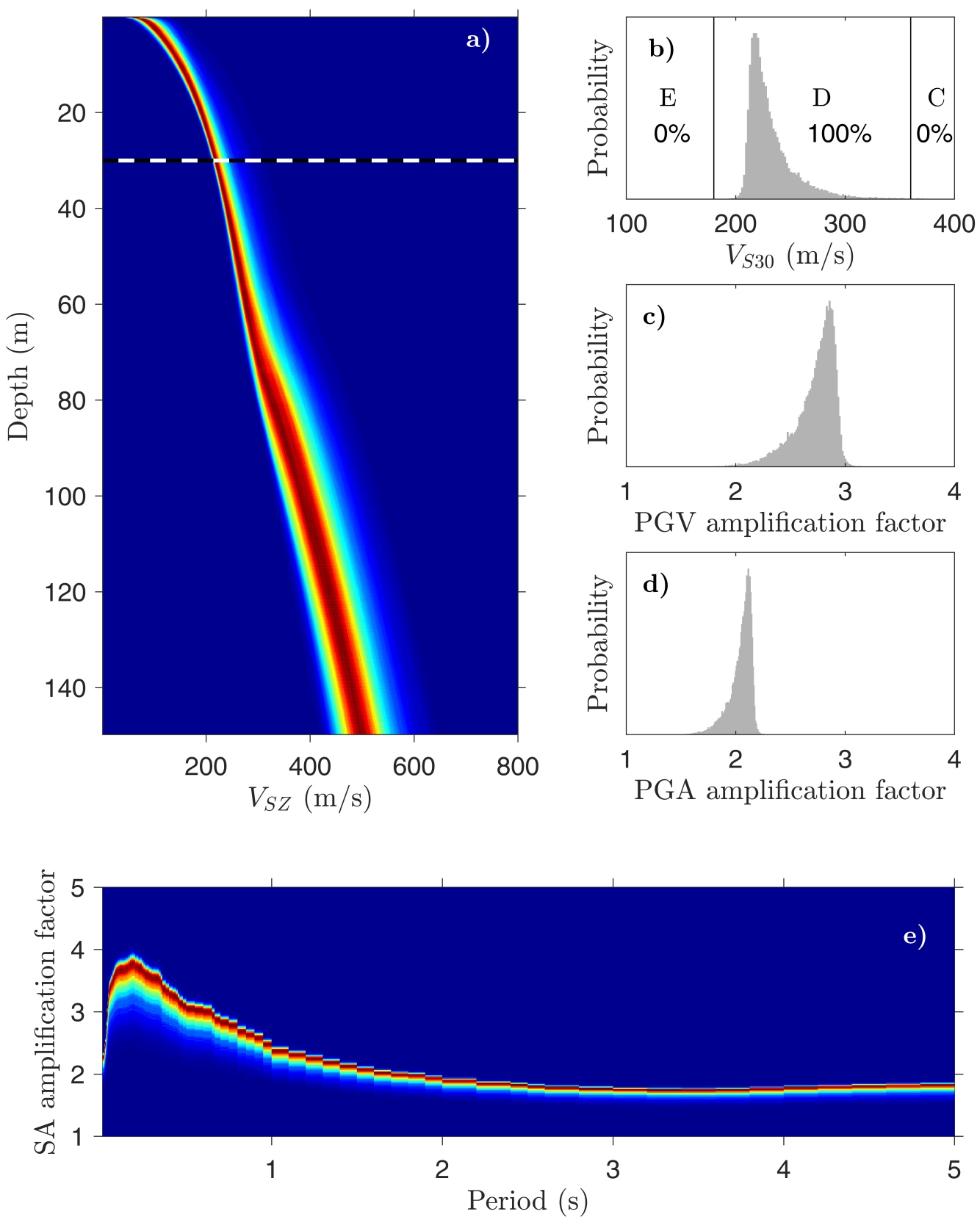
Figure 11: (a) $V_{S Z}$ probability density profile, (b) $V_{S 30}$ distribution, and $V_{S 30}$-dependent amplification factors for (c) PGV, (d) PGA, and (e) SA at Kitimat site 3. $V_{S 30}$ site classification boundaries (and probabilities) are shown in (b). The dashed line in (a) marks $30 \mathrm{~m}$ depth (i.e., delineates Vs30).
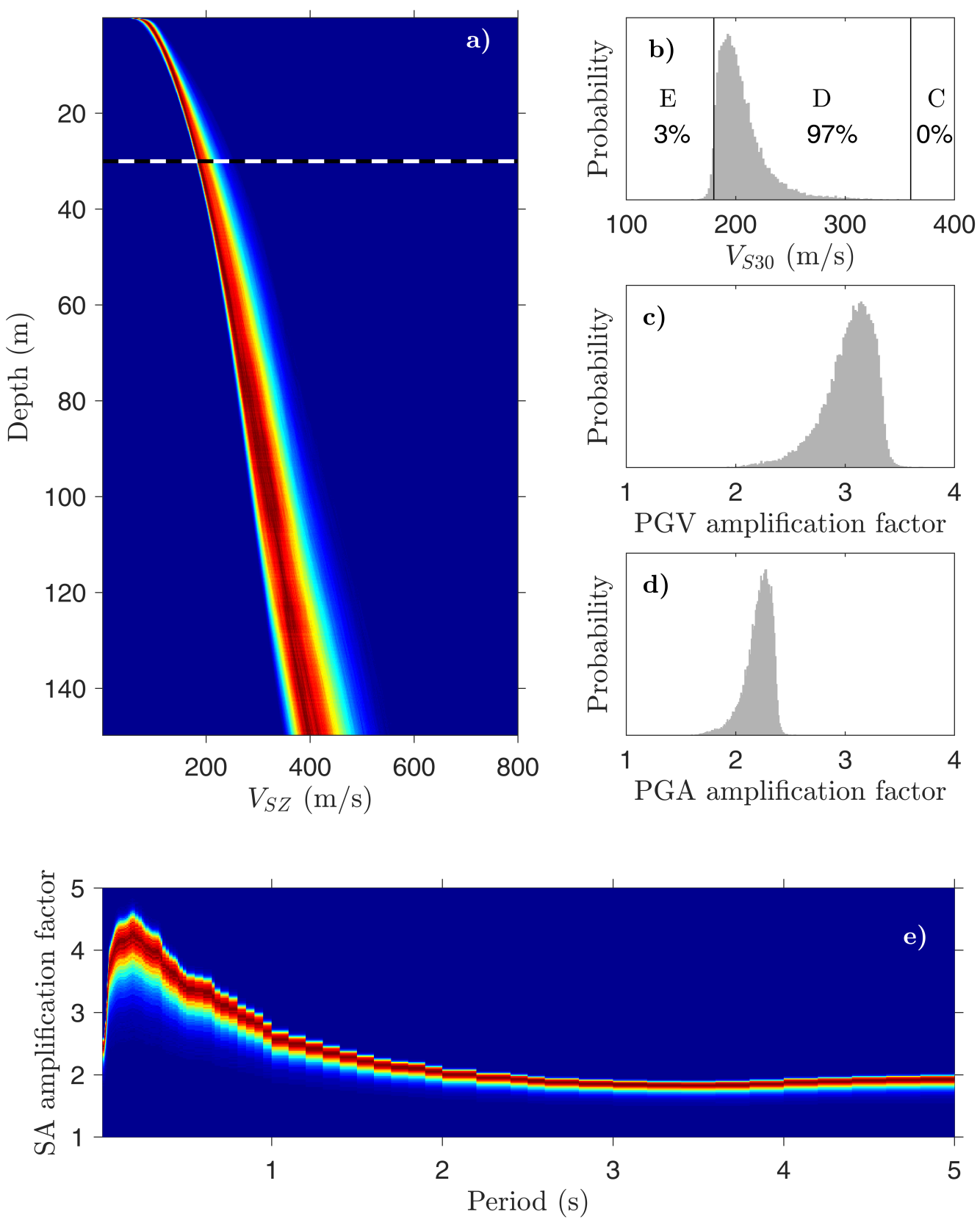
Figure 12: Probability densities of predicted amplification of $S_{H}$ waves at Kitimat sites 1, 2, 3 in (a), (b), (c), respectively.
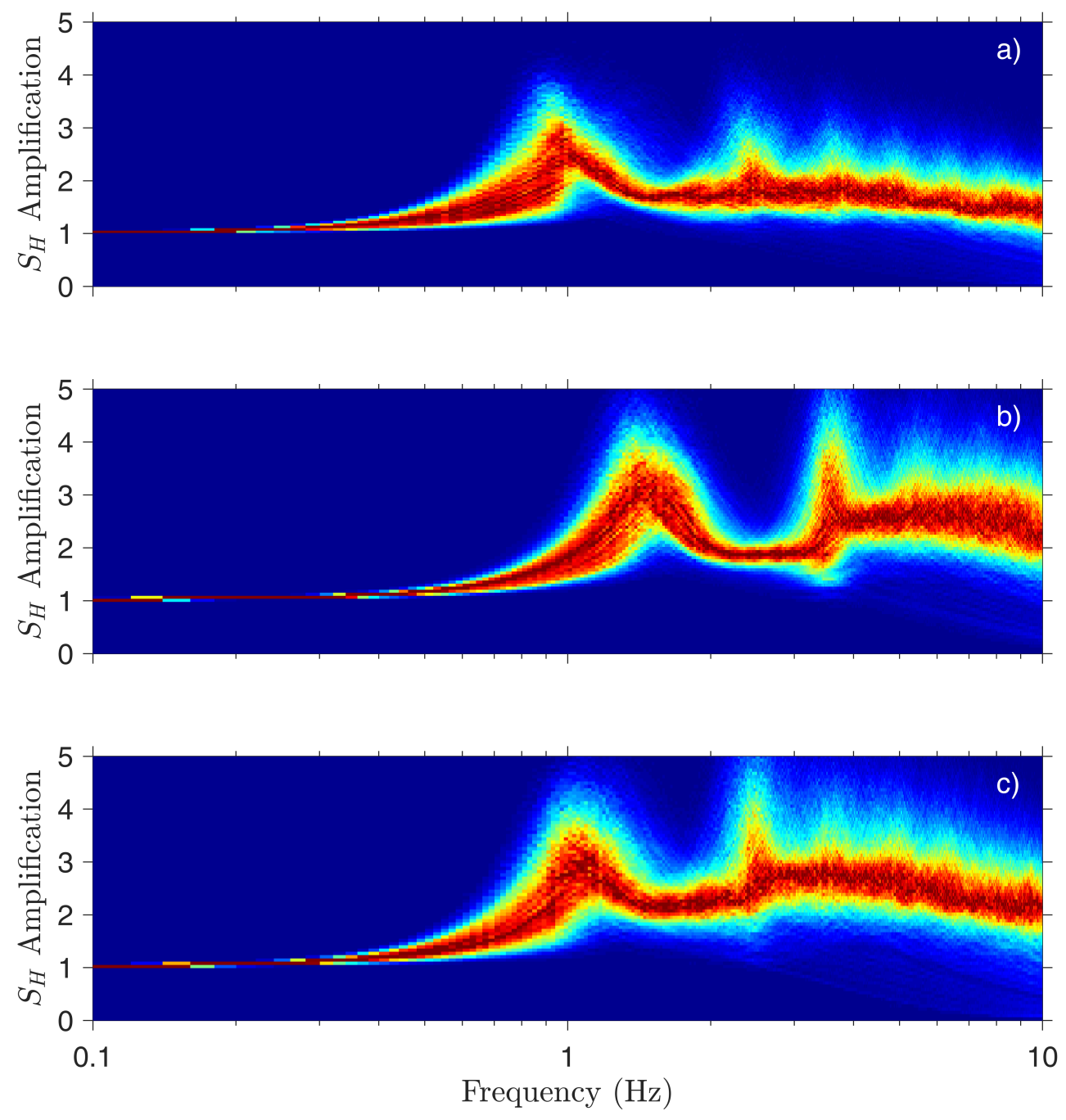